Articles and notes for discussion were received from all parts of the world, the bulk naturally coming from the British Isles, but in the past year contributions were sent also from America, India, Australia and Holland. A large number of books is being received from publishers for review.

The Journal seems to have acquired a recognised place in the learned world. The Managing Committee, however, believes that there is still much room for improvement. It is their intention to publish from, time to time numbers devoted to special topics. A further plan is to encourage the publication of articles on the history of scientific ideas, and of studies of philosophers of science of the past. The development of these subjects will depend on suitable papers being offered for publication. With the object of establishing a high standard of reviewing, a leaflet has been prepared for the guidance of reviewers:

\title{
Problems and Theories of Causation
}

\author{
By REGINALD O. KAPP, B.Sc., M.I.E.E. \\ (Professor Emeritus in the University of London) \\ $A B S T R A C T$ of Paper read on 10th December, 1951.
}

In spite of their great wisdom in many things the Ancient Greeks did not understand the nature of a cause in physics. In personifying the forces of nature they attributed the same kind of cause to events in the inanimate world that we observe in everyday human affairs. They did so when they attributed the tides to control exercised by the sea god Neptune. To-day we associate the moon with the tides. And to do so is to make a far more significant change than one of mere name from Neptune to moon. It is that modern thought has introduced the concept of causation without control. The Ancient Greeks could only think in terms of causation with control, be the control exercised by a human being or by a very anthropomorphic god.

We also do sometimes speak in terms of causation with control. We do so when we say that longing for a smoke causes a person to light a cigarette, or that the need to sew on a button causes someone to thread a needle, or that a desire to increase output in a factory causes the works manager to engage more hands. In such examples the cause is said to be someone's decision and the effect is attributed to that person's control of the course of events ; cause and effect are mentioned in terms of aim and achievement; the person said to cause the event is thought of as a centre of control and as exercising such teleological functions as guidance, selection, discrimination, co-ordination. It was by the exercise of such functions that the Ancient Greeks thought of Neptune as causing the tides. But we do not think of the moon as doing anything remotely similar.

We know that the moon does not reach decisions, that it does not have an aim, that it does not exercise any teleological functions. We do not regard it as a centre of control in the sense in which the Greeks regarded Neptune as a centre of control. For we know that the tides result from a combination of circumstances of which the moon's position is but one, the earth's rotation being another, the coastline and the wind yet others, and to which every field 
of force contributes some share. We now recognise the physicist's universe of discourse as one in which there is unrestricted interaction between all its component parts. In such a universe the cause of any event can only be stated completely as everything that has ever happened; as also the effect of any event is manifest to some extent in every future one. In such a universe there is causation, but there can be no control.

Symmetrical patterns may occur there occasionally, as when jostling, uncontrolled molecules form a crystal ; but things are never guided into such patterns. The end of a piece of cotton might just conceivably be wafted by a breeze through the eye of a needle, but one would not expect it to happen. This is what those mean who say that the inanimate world is governed by chance and not by design.

To say this is obviously to deny that such a world can manifest specified order; or that it can manifest organisation. For when we say that a thing has been organised we mean that its component parts are so interrelated as to serve some purpose. If we mean less we use words in a misleading sense. It is thus, for instance, that we speak of the organisation in a factory and that we call a machine or a living organism an organised structure.

Every physicist knows this. But Greek thought was very potent and there are still many scientists who assert that both specified order and organisation are manifest in the physicist's universe of discourse ; among the constellations, for instance. Causation without control has not been properly understood by all scientists even yet.

If one could prove that causation without control can lead to specified order and organisation certain very difficult problems would disappear; they would be explained away. And so it is natural that attempts should be made from time to time to prove this. But they have all been too naïve to succeed. Control, guidance, selection, discrimination, co-ordination are realities, as are their results in specified order and organisation. The challenge of these must be faced and not dodged. Specified order and organisation are to be found, not only in human affairs as in the threading of needles and the organisation of factories, not only as a result of consciousness, but also, as many biologists have pointed out, in the whole of the organic world. And they are not to be found in the absence of life.

An example of specified order and organisation is provided by a factory in which a heavy casting is being moved by a crane. The operation requires a supply of energy, the path for which can be traced from the sun through giant forest trees of the past, through coalfields, through the boilers, turbines and transformers in the electric power station, through cables and the crane motors. If energy were the only commodity required for the performance of the casting this would provide an example of causation without control, as is done by the tides. But in fact a second commodity is also required. One might call it control, though Professor Kapp preferred the word used in his books, namely "diathesis" meaning literally the process of arranging things to meet a specification.

A path for the control, or diathesis, can be traced backwards from the casting through contactors adjacent to the crane motors, through electric wires from the crane cabin, through pushbuttons and handles in that cabin, through the muscles of the craneman's hands, the endplates joining muscle fibres to his nerves, the nerves that connect to the brain, synapses there. Such a path provides material evidence that there is causation with control, just as the written instructions received by the foreman provide documentary 
evidence. The existence of a path for control in the foundry and its absence in the physicist's world of unrestricted interaction marks a distinction of great scientific significance.

Paths for diathesis should, therefore, form an important field of study. Among interesting facts about them one may mention a few rather obvious ones. They are material paths, with an objective reality. The controlled process would not be as specified if they were broken anywhere. They transmit diathesis in one direction only. They are consumers of energy, but not transmitters. They consist of devices that can be accurately described in engineering terms as relays connected in cascade. The energy consumed by such paths may be, and often is, very much less than the controlled energy. Every path for diathesis that plays a part in human affairs has its origin in a human brain. Many such paths do not extend beyond the human body; that the path in the foundry does so proves only that man is a tool-using animal. And the same basic significance belongs to the part of the path that is outside and the part that is inside the body. The significant distinction is not, as too often supposed, between living and lifeless mechanisms, but between what Professor Kapp calls diathemes (which include machines) and adiathetous structures.

One of the biggest and most difficult problems raised by the existence of paths for diathesis is to discover the source of this commodity. If the cascaded relays along any such path are numbered, one can say that relay number three is controlled by relay number two and that relay number two is controlled by relay number one. But there the recital must cease. Although the craneman in the example given is influenced by observations made on his environment, although these are stimuli, they are not selected for him as the switches and pushbuttons are selected for the casting. They have not been subjected to a diathesis and do not occur along the path for one. They reach the organs of sense perception indiscriminately. In short, a path for diathesis is observable on the efferent side of the nervous system and not on the afferent side.

So one must beware of facile interpretations of control in terms of stimulus and response. No alternative seems possible to the conclusion that the source of every diathesis, while real, is nevertheless without location. 